\title{
Exploring the Relationship between the CPI and the PPI: The Colombian Case
}

\author{
Wilmer O. Martinez R. ${ }^{1}$, Edgar Caicedo G. ${ }^{2}$ \& Evelyn J. Tique C. ${ }^{2}$ \\ ${ }^{1}$ Statistics Section, Banco de la República (Central Bank of Colombia), Colombia \\ ${ }^{2}$ Programming and Inflation Department, Banco de la República (Central Bank of Colombia), Colombia \\ Correspondence: Martinez Rivera Wilmer Osvaldo, Statistics Section, Banco de la República (Central Bank of \\ Colombia), Colombia. E-mail: wmartiri@banrep.gov.com
}

Received: May 29, 2013

Accepted: June 4, 2013

Online Published: August 21, 2013

doi:10.5539/ijbm.v8n17p142

URL: http://dx.doi.org/10.5539/ijbm.v8n17p142

\begin{abstract}
This article explores the nature of the existing relationship between the Producer Price Index (PPI) and the Consumer Price Index (CPI). In particular, it seeks to determine whether the PPI can be considered a leading indicator of the CPI, using the methodology of coincident profiles proposed by Martinez (2010), which modifies the one presented by Banerji (1999). Previous studies for Colombia and other countries found links of all types between these two price indexes. Yet, there is no evidence of previous studies that have eliminated the methodological differences between the two baskets, at least in the international literature reviewed for this article. However, when these discrepancies are removed (homogenization of items and weights), desirable results are found for the Colombian case; namely, the PPI leads the CPI and, depending on the analyzed group, this leadership might anticipate evolution of the CPI by one month or even more. These findings clearly are useful as input to improve consumer inflation forecasting models and the monetary authority's decision-making process.
\end{abstract}

Keywords: CPI, PPI, price formation and pass-through, coincident profile, turning points

\section{Introduction}

Most countries in the world calculate a Producer Price Index (PPI) and a Consumer Price Index (CPI). Both have a broad range of uses, such as calculating consumer and producer inflation, which are key instruments for steering monetary policy. They also are used as input to adjust fees, prices, and wages, and to index a large quantity of economic information. Given the usefulness and importance of these indexes, there have been several studies in international literature in recent decades that try to analyze the nature of the long-term relationship between the PPI and the CPI and, in particular, the ability of the first to anticipate the evolution of the latter.

Different results have been found, ranging from the PPI as a leading indicator of the CPI to a coincident relationship between them, or even the CPI anticipating the PPI. The main explanations for the differences between the performance of the PPI and the CPI have been price controls, supply and demand factors, adjustments in retail margins, and differentials in pass-through of the exchange rate, among many others. However, there has not been a profound analysis of the methodological differences between both baskets.

In Colombia, few studies have focused on the leading relationship of the PPI to the CPI. Hence, this document constitutes a new attempt, as of another known article, to move forward in understanding this relationship, but with the particularity of minimizing the methodological differences between both price indexes, so as to better identify the type of link that characterizes the PPI and the CPI in Colombia.

Section 1 of this document corresponds to this introduction. The rest of the document is organized as follows: Section 2 describes the methodological and conceptual aspects of the CPI and the PPI; the literature review is in the third section, while the statistical methodology used to find the leadership of the PPI is in Section 4. The exercise for splicing the series and harmonizing the baskets is found in the fifth section, along with a discussion of the results. Section 6 contains the conclusions.

\section{Methodological Aspects of Price Indexes}

In Colombia, the National Department of Statistics (DANE, in Spanish) is the entity in charge of publishing the two main price indicators: the Consumer Price Index (CPI) and the Producer Price Index (PPI). (Note 1) It is 
important to highlight the main differences between these two baskets, since their conceptual and methodological discrepancies impede any comparison between both price indexes, and constitute the main explanation when there is no leadership from the PPI to the CPI or there is no long-term relationship between them.

The CPI aggregates the prices of goods and services for mass consumption and makes it possible to identify the evolution of inflation at the end of the supply chain. Meanwhile, the PPI computes the prices of a basket of goods, at their first level of sales, which are part of the total domestic supply in the economy (produced and consumed, and imported). The CPI has nationwide coverage that includes 24 cities; the PPI is also national, but the basket is not divided by regions or cities. The PPI basket is broader, as it includes most of the prices traded in the economy (except for services); whereas the CPI covers only the basic basket for household consumption. The weights of the PPI were obtained using the DANE National Accounts, specifically those for production; the weights for the CPI were built on the latest Income and Expenses Survey. This means the relative importance of the same items can vary considerably between both baskets. For instance, coffee has a high weight in the PPI and a low one in the CPI. Also, the PPI is more tradable in nature, as it excludes services, which tend be non-tradable. In the PPI, the mining sector carries considerable weight; while the CPI includes only fuel and gas. (Note 2) The aforementioned conceptual and methodological differences hinder a comparison between both price baskets, at least in the Colombian case.

\section{Literature Review}

Internationally, there is extensive literature exploring the nature of the existing relationship between the CPI and the PPI. Surveying the most recent articles on the subject and for different countries revealed there is no definitive evidence on the direction of the causality between both price indexes. However, a considerable part of the literature shows causality from the PPI to the CPI, and most of it analyzes price indexes at a highly aggregate level, thus paying little attention to their components.

For instance, in the article by Caporale et al. (2002), the authors analyze the nature of the existing relationship between the PPI and the CPI for the G7 countries during the period from January 1976 to April 1999. The methodology used involves the estimation of a bivariate vector autoregressive (VAR) model, whose results point to one direction Granger (1969) causality from the PPI to the CPI in France and Germany. The causality occurs in both ways in Italy, Japan, the United Kingdom and the United States, while in Canada there was no evidence of causality.

Ghazali, Yee and Muhammed (2008), using monthly data from Malaysia between January 1986 and April 2007, explored the link between the PPI and the CPI. The authors ran two types of tests: the error correction model developed by Engle and Granger, and the non-causality test by Toda and Yamamoto. Notwithstanding the methodology used, these authors found a unidirectional causality from the PPI to the CPI.

Gang et al. (2008), studying the relationship between the PPI and the CPI based on monthly data for China, found a long-term connection between them. They also discovered a bi-directional causality, with the one that goes from producer prices to consumer prices being the strongest. The long-term link between the two baskets was identified using Johansen's integration method, while the nature of the causality between them was established with the test by Toda and Yamamoto (1995).

Sidaoui et al. (2010), using an error correction model and Granger's causality test for monthly variations in Mexican prices, found there is long-term cointegration between both indexes and causality goes from the PPI to the CPI.

Akcay (2011) conducted a study in which he examined the causality relationship between the PPI and the CPI for five selected European countries, using seasonally-adjusted monthly data between August 1995 and December 2007. He used the causality test by Toda and Yamamoto (1995), and the results suggest the existence of unidirectional causality from the PPI to the CPI in Finland and France, and bi-directional causality between the indexes in Germany. For the Netherlands and Sweden, there is no significant evidence of causality.

Finally, Muhammad et al. (2012) analyze the Granger causality in the frequency domain between the CPI and the WPI in Pakistan, pursuant to the methodology proposed by Lemmens et al. (2008), using monthly data between 1961 and 2010. These authors found the causality between the CPI and the WPI varies, depending on the frequency domain. They also discovered the CPI Granger-causes the WPI in low and medium frequencies, as well as in high frequencies, which reflects long, medium and short-term cycles. The foregoing is based on decomposition of the causality for different time horizons.

According to the aforementioned review, it is possible to conclude that the most common methodologies to 
study the relationship between price indexes are: vector autoregressive (VAR) models or even Bayesian vector autoregressive (BVAR) models, together with Granger causality tests; or vector error correction models (VECM), together with the Granger causality test; or the one modified by Toda and Yamamoto (1995).

All of the studies noted above analyze the relationship between two aggregated indexes, but none explores the coincident items that comprise the PPI and CPI baskets. The research by Fan Gang, He Liping and Hu Jiani (2009) on the Chinese economy mentions the differences between both baskets, emphasizing the considerable discrepancies that exist among the weights of each of the components of the baskets. However, they make no correction for the methodological differences of the weights and the coincident items, which could have led to a more accurate and detailed observation of the existing link between both baskets.

In Colombia, the relationship between the CPI and the PPI has not been studied widely. The only known paper on the subject is the one by Huertas and Jalil (2000), who use the econometrical cointegration methodology, but found no evidence of a relationship between the annual changes of the total CPI and the total PPI. Given these results, the authors concluded the series are not completely comparable. So, the appropriate method is to use the CPI excluding services and to contrast it with the end-consumption PPI. An analysis of the annual variation in these series showed they exhibit common trends (i.e. they react in the same direction) in the long run.

An additional test conducted in this study tried to identify the causality of the series to determine whether one series could anticipate the behavior of the other. The results of this article show a bi-directional causality; namely, the changes in the end-consumption PPI cause those of the CPI excluding services, and vice versa. This study also involves a disaggregate analysis for two groups: food and medicines, and finds there is coincidence in the case of food and causality going from the PPI to the CPI for medicines.

\section{Conceptual Framework}

To determine the nature of the existing relationship between the CPI and the PPI, we first analyze the turning points of the two series, using the methodology proposed by Bry and Boschan (1971) to estimate them. Secondly, we employ the methodology developed by Banerji (1999), as modified by Martinez (2010), to compare the inflection points of the price indexes in question. Each of these methodologies are described briefly as follows.

\subsection{Turning Points}

The concept of a turning point was designed initially to identify the economic cycles of a country. The turning points of a time series are the points in time where there is a local maximum or minimum. These points define the periodic behavior of the series and are related to the booms and recessions that are characteristic of the economy. The segment comprised between two maximums (or two minimums) is known as a cycle, and the one between a maximum and a minimum (or vice versa) is known as a phase (recession and boom).

To identify the turning points of a time series, Bry and Boschan (1971) recommend bearing in mind some of the aspects suggested by the National Bureau of Economic Research (NBER) in the United States. The procedure is performed on seasonally-adjusted series and involves successively applying a set of rules to identify the turning points in a sequence of filtered series with different degrees of smoothing. (Note 3)

\subsection{Banerji's Proposal to Evaluate Leading Indexes}

Banerji (1999) proposes a methodology to evaluate the candidate indicators to be a leading index, based on Fisher's randomization test for matched pairs (see Lehmann and Romano (2005)), which is used because it does not require assumptions about the distribution of the number of differences between the turning points of the reference series and the index in question. To do so, we calculate the distance between the turning points of the reference series and its corresponding points in the candidate indicator, previously obtained using the algorithm by Bry and Boschan (1971) to determine if the break points of each indicator occur in advance of the turning points of the reference series. Thus, assuming that Q turning points are observed in each of these series, Q differences can be obtained in the form of $\pm \mathrm{d}_{1}, \pm \mathrm{d}_{2}, \ldots, \pm \mathrm{d}_{\mathrm{Q}}$, for a total of $2^{Q}$ possible differences, at the most. The calculation of each difference is found between the maximum and minimum points across time; namely, $d_{i}=t_{1 i}-t_{2 i}$, where the sub-indexes 1 and 2 denote the two indicators being compared. However, if the number of turning points $Q$ is different, the difference $d_{i}$ is calculated between the points in time where the common inflection points are closest to each other (maximum-maximum or minimum-minimum).

Since the objective of Banerji's proposal is to determine whether the turning points of the indicators that are candidates to be leading indexes occur in advance of the breaking points of the reference series, he suggests testing the following hypothesis: 


$$
H_{0}: \sum_{i=1}^{Q} d_{i}=0 \quad \text { against the alternative } H_{1}: \sum_{i=1}^{Q} d_{i}>0,
$$

The first step in testing $H_{0}$ is to add the observed differences. Then, negative signs are assigned systematically to each of the differences $d_{i}$, and the number of sums that are greater or equal to the observed sums of the $2^{Q}$ possible results is calculated. The number of results that fulfill the latter condition is denoted $R$ and, thus, the null hypothesis is rejected at a significance level of $R / 2^{Q}$. This is applied to the differences between maximums and minimums individually. For more details, see Banerji (1999).

Now, since the objective of Banerji's (1999) proposal is to evaluate the indexes that could be the leading indicator, if the null hypothesis is rejected the question to answer is: how many leading periods does the indicator exhibit with respect to the reference series?

\subsubsection{Number of Leading Periods of the Leading Indicator}

To determine if the candidate indicator leads the turning point of the reference series in at least one month, subtract one unit from each of the observed differences; that is, $d_{i}-1$ where $i=1, \ldots, Q$. Using these new differences, perform the hypothesis test proposed in (1) and this will determine the significance level at which the null hypothesis (the indicator is not a leading index by one period) can be rejected.

Following this procedure, it is possible to determine if the number of leading periods is larger than $2,3, \ldots, K$ for the turning points of the reference series by merely subtracting $2,3, \ldots, K$ from the observed differences and performing the respective tests. With the significance levels for each number of leading periods, a bar graph is constructed that shows the relationship between the confidence level at which the null hypothesis is rejected (given by $100\left(1-R / 2^{Q}\right) \%$ ) and the number of leading periods. This graph is known as the lead profile.

\subsection{Coincident Profile, a Modification of Banerji's (1999) Proposal}

The hypothesis to be tested in the construction of the leading profile proposed by Banerji (1999) can be represented as:

$$
H_{0}^{(l)}: \sum_{i=1}^{N}\left(d_{i}-l\right)=0 ; \quad l=0, \pm 1, \ldots, \pm m
$$

Where the value of $l>0$, for which the null hypothesis is not rejected, is the lead period.

Since the objective of this article is to determine the nature of the relationship between the CPI and the PPI, Martinez (2010) designed a methodology based on Banerji's (1999) proposal that allows for determining if the studied indexes are coincident, lagged, or if one leads the other.

Under these conditions, Martinez (2010) formulates the construction of a bar diagram in which the height of each bar is the p-value (whose calculation is presented below) of test (2) for each value of $l$. The coincident profile diagram was obtained following this procedure. The proposed methodology makes it possible to determine if two indexes are coincident, lagged, or if one leads the other. A coincident index shows a coincident profile diagram for $l=0$, denoting the highest p-value. In the case of a leading index, the focus is on the positive values of $l$; so, if one index is expected to lead the other by $l=k$ periods, with $k>0$, then the p-value for this period would be the highest. In this sense, it can be said that a leading indicator Granger-cause the other index (see Lutkepohl (2009), page 10).

\subsubsection{Permutation Test}

The permutation test for two independent samples is based on the rejection of the null hypothesis in favor of a specific alternative, if the established significance level is greater than the corresponding $\mathrm{p}$-value.

The procedure to calculate an approximated $p$-value is equivalent to the permutation test based on the difference in means, as described below:

(i) Calculate the sum of the differences of the turning points of the candidate series with the reference series; that is, $D_{0}=\sum_{i=1}^{Q} d_{i}$, where the $d_{i}$ 's are defined in section 4.2.

(ii) Allocate signs to the observed differences; that is, $\pm d_{1}, \pm d_{2}, \ldots, \pm d_{Q}$ for a total of at most $2^{Q}$ possible randomizations (samples). 
(iii) Calculate the sum $D_{i}$ for each of the possible samples of the $d_{i}$ 's of the previous step.

(iv) For the bilateral test, the $p$-value is given by:

$$
P_{0}=\frac{\#\left\{D_{i}:\left|D_{i}\right| \geq\left|D_{0}\right| ; \quad i=1,2, \ldots, 2^{Q}\right\}}{2^{Q}},
$$

Where: $\#\left\{D_{i}:\left|D_{i}\right| \geq\left|D_{0}\right| ; \quad i=1,2, \ldots, 2^{Q}\right\}$ denotes the number of samples that fulfill the condition $\left|D_{i}\right| \geq\left|D_{0}\right|$ where $D_{0}$ is the observed difference.

\section{Harmonized CPI PPI Series and Results}

\subsection{Harmonized CPI and PPI}

The period considered in this analysis goes from January 1991 to June 2012. During that time, both the CPI and the PPI suffered from several methodological changes, considering the modification in the composition and weights of the baskets. This made it necessary to splice the price series of the CPI (at a basic level of expenditure) and that of the PPI (at a subclass level) for three different methodologies. On the one hand, the methodologies CPI-60 (December 1988-December 1998), CPI-1998 (December 1998-December 2008) and CPI-2008 (starting in December 2008) were spliced. Then, the methodologies PPI base 90 (December 1990-June 1999), PPI base 99 (June 1999-December 2006) and PPI base 2006 (starting in December 2006) were spliced.

To analyze the evolution of both the CPI and the PPI in recent years and the nature of the link between them, the first step was to make both indexes comparable. To do so, we used the same base year, which corresponds to the one of the CPI (December 2008=100). The next step was to determine the appropriate level of disaggregation for each index, so as to make it possible to find a match in the PPI for each item of the basic level of expenditure in the CPI.

The chosen level for the CPI was the one for basic expenditure, as it is the most disaggregated and is available to the public. This sub-basket is composed of 181 items, from which the 50 basic expenses that correspond to services were excluded. Each of the 131 remaining items in the CPI was assigned to a subclass of the PPI, which is also the highest official disaggregation published by DANE (see Attachment 1, Martinez et al. (2012)).

However, due to methodological changes in both baskets, some series do not have sufficient historical information, so only 100 items in the CPI were found to have a matching item in the PPI of domestic supply.

\subsection{Results}

This document analyzes the relationship between the PPI and the CPI. Accordingly, we used the econometric technique of lead indexes proposed by Banerji (1999) and modified by Martinez (2010), as previously explained. First, we analyzed the same series used by Huertas and Jalil (2000); namely, the total PPI and the total CPI between January 1991 and June 2012. Likewise, we identified the nature of the existing relationship between the CPI excluding services and the end-consumption PPI.

The left panel in Figure 1 shows the performance of the annual variation in the total CPI and the total PPI, with the scale effect eliminated by subtracting the mean from each variable and dividing the result by its standard deviation. This graph shows both series follow a similar trend. In turn, the right panel shows the coincident profile diagram. In this graph, since the bar for lag -1 has the highest $p$-value, it is concluded the total CPI leads the total PPI by one period. (Note 4)

This result is unexpected, although there are similar findings in international literature. (Note 5) The lead of the CPI with respect to the PPI can be explained by the fact that the compared price baskets are very different in their components, weight structure, and tradability, among other factors. For instance, in the Colombian case, the participation of the non-coincident components (services in the CPI and intermediate consumption in the PPI) has been increasing in both baskets. In the PPI, with base June 1999, mining carried a weight of $2.7 \%$; in the current PPI, it increased to $4.4 \%$. In turn, services have gained participation in the representative consumer basket, having gone from $36.1 \%$ in the CPI with base December 1998 to $49.1 \%$ with the current methodology.

The PPI should exhibit the dynamic of the CPI in advance, because it constitutes the first step in the supply chain, while the CPI closes it and gathers the final retail prices. (Note 6) Several possible explanations emerge when this behavior is not observed. The most common are: changes in retail margins, price controls, supply and demand problems, differences in the pass-through of international prices and the exchange rate, difficulties in 
marketing goods, and different degrees of tradability of the goods in the supply chain. However, as will be shown in the Colombian case, the most important issue is elimination of the methodological differences between the two baskets to be able to find the actual existing link between the CPI and the PPI.

Now, if we try to close the conceptual gaps between the two baskets at the aggregate level; namely, by comparing the CPI excluding services to the end- consumption PPI, it can be concluded that the PPI leads the CPI by one period, as shown in the right panel of Figure 2. This contrasts with Huertas and Jalil (2010), who did not identify the PPI leading the CPI for the same aggregates, although they used a shorter sample period (December 1991-December 1999).

Since the aforementioned results identify a one-period lead of the PPI with respect to the CPI, we intend to analyze these indexes at a more comparable and disaggregated level to determine if there is further leadership from the PPI with respect to the CPI. To reduce the methodological differences between both price indexes to a minimum, we build a table of equivalences between the components of the PPI and the CPI (see Attachment 1 of Martinez et al. (2012)), and obtain a basket that is completely homogenous in descriptions, weights and comparison base, for both indexes.

We then confirmed if the differences in the weights between the baskets play an important role in the analysis. To do so, we initially compared the CPI-100 and the PPI-100, using their respective weights, then repeated the exercise after assigning the weights of the CPI to the PPI basket. (Note 7)
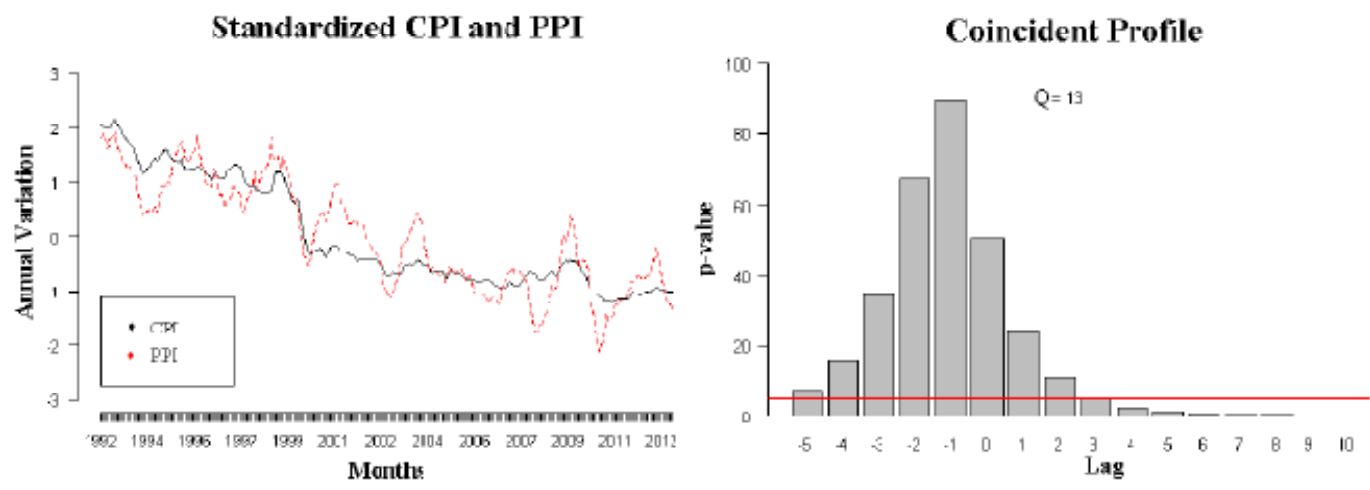

Figure 1. Annual variations in the CPI and the PPI and the coincident profile diagram

Sources: DANE and authors' calculations.
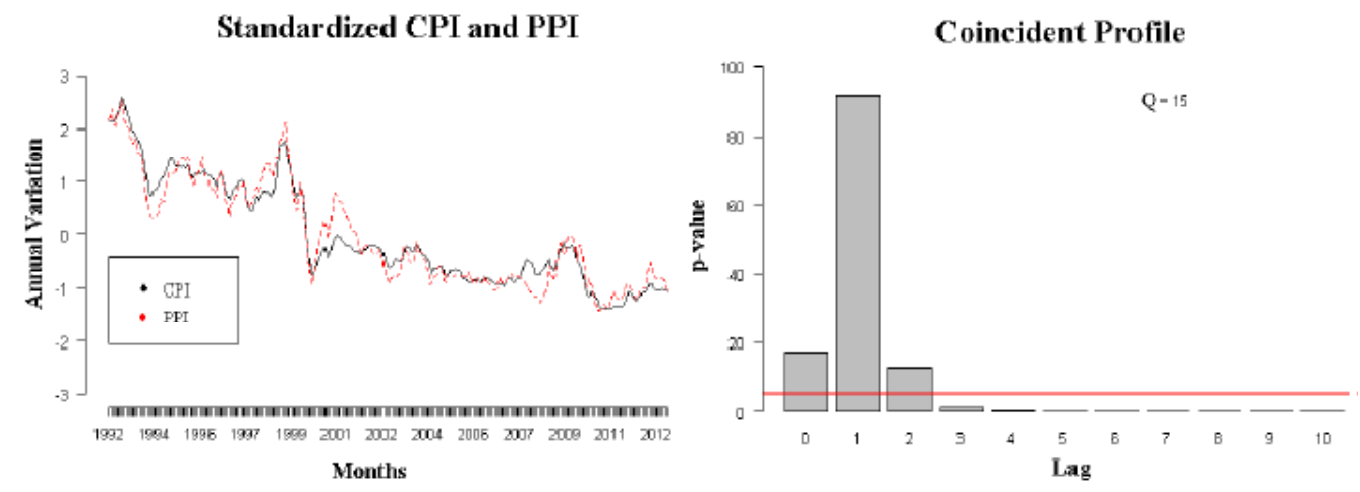

Figure 2. Annual variations in the CPI, excluding services, and the end-consumption PPI and the coincident profile diagram

Sources: DANE and authors' calculations.

Figure 3 shows the PPI-100, with its own usual weights, leads the CPI-100 by one month. Although this result is 
analogous to the one found using the CPI excluding services and the end-consumption PPI, the leadership in this case is stronger, as seen in the p-value in the right panel. However, if the PPI-100 and the CPI-100 are compared using the same weights, in this case those of the CPI, it is possible to conclude the PPI-100 leads the CPI-100 by two months (see Figure 4). This implies the difference in weights is, in fact, important when analyzing the nature of the existing relationship between both price indexes.
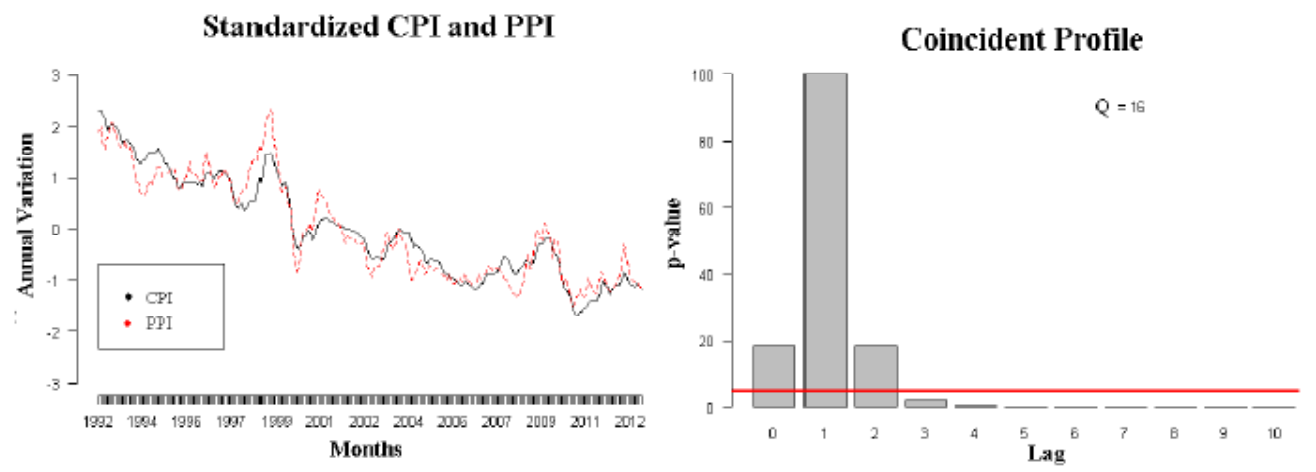

Figure 3. Annual variations in the CPI-100 (basic level of expenditure) and the PPI-100 (subclasses) with their own weights and the coincident profile diagram

Sources: DANE and authors' calculations.

Standardized CPI and PPI

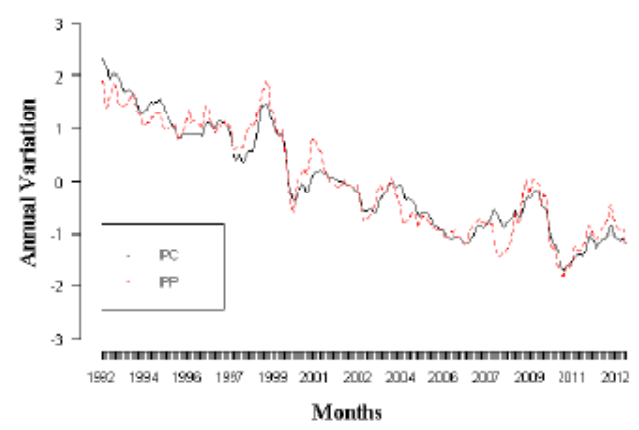

Coincident Profile

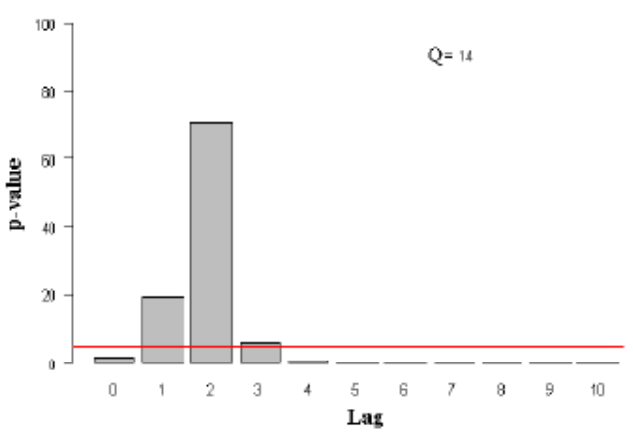

Figure 4. Annual variations in the CPI-100 (basic level of expenditure) and the PPI-100 (subclasses) and the coincident profile diagram

Sources: DANE and authors' calculations.

Once we have identified the number of periods in which the PPI-100 leads the CPI-100, using the weights of the CPI for both baskets, it is important to investigate the nature of the leadership found at further levels of disaggregation. In this case, the objective is to identify which groups of goods explain such leadership. To do so, we studied the 100 coincident items between both baskets and, adopting the standard grouping classification found in the DANE CPI, aggregated them into eight groups for both price indexes (Table 1).

Table 1. Relationship between the PPI-100 and the CPI-100, according to CPI DANE classification

\begin{tabular}{cccccccc}
\hline Clasif. & wgt_spl & wgt_real & Q & 0 & 1 & 2 & 3 \\
\hline Food & 18.80 & 28.21 & 15 & 1 & & & \\
Education & 0.79 & 5.73 & 11 & 1 & & \\
Health & 1.42 & 2.43 & 12 & 1 & & \\
Clothing & 4.40 & 5.16 & 11 & & 1 & \\
Housing & 4.00 & 30.10 & 14 & & 1 & \\
Others & 4.45 & 6.35 & 12 & & 1 & \\
Transportation & 7.43 & 15.19 & 14 & & & 1 & \\
Entertainment & 0.43 & 3.10 & 16 & & & & 1 \\
\hline
\end{tabular}


As show in the Table 1, wgt_spl is the Weight after splicing, wgt_real is the observed weights of each group in the CPI and Q is the number of turning points used in each comparison. 0, 1, 2 and 3 months of the PPI leading the CPI.

As shown in Table 1, the results are, in general, as expected. The prices of the food group in the PPI-100 do not lead those registered in the CPI-100, which is normal due to the high turnover and perish ability of this segment of the representative consumer basket. Likewise, the education and health price indexes in the PPI-100 are coincident with the prices of the same groups in the CPI-100. (Note 8) The result, in the case of education, is not surprising, because school supplies and books tend to have a high turnover during two periods of the year (January-February and August-September); although there might be a marked lead of the PPI-100 with respect to the CPI-100 during the other months. The coincidence in the health sub-baskets might be associated with the mass consumption of over-the-counter medicines such as painkillers, vitamins, flu medications, etc.

The nature of the relationship between producer and consumer prices for the remaining groups of goods is clearer (other expenses, transportation, clothing, housing, and entertainment). We found leadership from the PPI-100 with respect to the CPI-100. In summary, the prices of these five groups in the PPI-100 lead the prices of the CPI-100 by one to three months, just as expected.

We also conducted another exercise in which the two baskets in question were classified between food, tradable and non-tradable items (Table 2). (Note 9) As shown in Table 2, in the food group, the prices of both indexes are coincident. With respect to the non-tradable component, the PPI-100 was found to lead the CPI-100 by a month. In the case of tradable goods, it was observed the PPI-100 leads the CPI-100 by 5 months.

Table 2. Relationship between the PPI-100 and the CPI-100, according to classification food, tradable and non-tradable

\begin{tabular}{|c|c|c|c|c|c|c|}
\hline Clasif. & wgt_spl & wgt_real & Q & 0 & 1 & 5 \\
\hline Food & 18.80 & 28.21 & 15 & 1 & & \\
\hline Non-Tradable & 3.37 & 45.78 & 14 & & 1 & \\
\hline Tradable & 18.64 & 26.00 & 14 & & & 1 \\
\hline
\end{tabular}

As show in the Table 2, wgt_spl is the Weight after splicing, wgt_real is the observed weights of each group in the $\mathrm{CPI}$ and $\mathrm{Q}$ is the number of turning points used in each comparison. 0,1 , and 5 months of the PPI leading the CPI.

Several studies confirm the pass-through of movement in the exchange rate and international commodity prices to producer prices is greater than the pass-through to consumer prices. (Note 10) Moreover, the pass-through of fluctuations in the exchange rate and international prices to the PPI has less of a lag than the one observed for the CPI. These findings help to explain why the PPI-100 for tradable goods leads the tradable CPI-100 by several months, since it is affected more rapidly and intensely by the exchange rate and international prices than the CPI

Given the aforementioned results, one can conclude the PPI-100 leadership with respect to the CPI-100 is explained by the non-food component and, within this group, by the group of tradable goods, due to the superior tradability of the PPI and its added sensitivity and more rapid response to changes in the exchange rate and in international prices (especially for food and commodities).

Finally, there are several studies in specialized literature that find all kinds of relationships between the CPI and the PPI. However, by closing the gap between the methodological differences, the predictive content of the PPI on the CPI is clearly observed, mainly in its tradable component. Therefore, these results could be used to improve CPI forecasts and the monetary authority's decision-making process.

\section{Conclusions}

1) The findings outlined $\mathrm{n}$ specialized literature on the relationship between the PPI and the CPI are not conclusive. Even surprising results, such as the CPI causing the PPI, have been found. Other studies have shown coincidence between the prices of both baskets in some countries, but many others provide evidence that the PPI leads the CPI, which is in line with expectations, provided the PPI is seen as a link that precedes the CPI in the supply chain.

2) In national literature, aside from this paper, there is only one other known article, which found a 
coincidence relationship between the PPI and the CPI. This simultaneity between the prices of both these baskets has been explained in international literature by factors such as methodological and conceptual differences, price controls, demand and supply factors, and adjustments in retail margins, among others.

3) The two price baskets examined in our study are widely different in terms of size, coverage, location of the supply chain, origin and structure of the weights, tradability, composition, etc. These conceptual and methodological differences complicate a comparison between the two baskets. Accordingly, some studies, as seen in the Colombian case, do not find any type of leadership or long-term relationship between them.

4) The aggregate value of this document is, first of all, implementation of the methodology of coincident profiles to identify the relationship between price indexes. This technique, besides establishing causality relationships, also allows for identifying the nature of the relationship between several indicators. Moreover, the analysis incorporates a unification of descriptions and weights between the CPI and PPI baskets, which, at least in the reviewed literature, had not been considered. This exercise led to a clear identification of the nature of the existing relationship between both price indexes.

5) Using the methodology of coincident profiles for the Colombian case, it was found that, if the methodological differences between the studied baskets are preserved, the total CPI surprisingly leads the total PPI by one month. However, when these methodological gaps are closed; namely, when the CPI excluding services is compared to the end- consumption PPI, we find the PPI leads the CPI by one month, just as expected. Finally, when refining the comparison (100 coincident items between the two baskets and the CPI weights are used to aggregate both price indexes), we see the PPI-100 leads the CPI-100 by two months.

6) Using a more disaggregated analysis of the CPI-100 and the PPI-100, we find the non-food component is the one that concentrates the leadership from producer prices to consumer prices. Classifying both price indexes into food, tradable and non-tradable goods, we see the food PPI is coincident with the same group in the CPI. This is to be expected, due to the perish ability of food items and their high turnover. The prices of the non-tradable component of the PPI lead those of the same group in the CPI by one month. Producer prices for tradable goods, besides leading their CPI counterpart by several months, also concentrate the leadership from the PPI to the CPI. This is explained by the fact that the PPI is more tradable than the CPI, and because the pass-through of international commodity prices and the exchange rate occurs with greater speed and intensity in the PPI than in the CPI.

\section{Acknowledgments}

We wish to thank Eliana Gonzalez (Head of the Statistics Section), Carlos Huertas (Head of the Programming and Inflation Department) and Adolfo Cobo (Head of the Inflation Section) for their valuable comments and suggestions. The opinions and possible errors in this paper are exclusively the responsibility of the authors, and the content does not involve Banco de la República or its Board of Directors.

\section{References}

Akcay, S. (2011). The causal relationship between producer price index and consumer price index: Empirical evidence from selected European countries. International Journal of Economics and Finance, 3(6), 227-232. http://dx.doi.org/10.5539/ijef.v3n6p227

Banerji, A. (1999). The lead profile and others non-parametric tools to evaluate survey series as leading indicators. Economic Cycle Research Institute, CIRET Conference Willington, New Zealand, March. Retrieved from http://ecri-prod.s3.amazonaws.com/reports/samples/2/lead_profiles.pdf

Bry, G., \& Boschan, C. (1971). Cyclical analysis of time series: Selected procedures and computer programs. National Bureau of Economic Research, New York.

Caicedo, E. (2006). El impacto de la tasa de cambio sobre los precios. Inflation Report, June 32-36, Banco de la República de Colombia. $\quad$ Retrieved from http://www.banrep.gov.co/documentos/publicaciones/inflacion/2006/informe_jun_06.pdf

Caporale, G. M., Katsimi, M., \& Pittis, N. (2002). Causality links between consumer and producer prices: some empirical evidence. Southern Economic Journal, 68, 703-711. http://dx.doi.org/10.2307/1061728

Engle, R., \& Granger, C. (1987). Cointegration and error correction: Representation, estimation and testing. Econometrica, 55, 251-276. http://dx.doi.org/10.2307/1913236

Frankel, J. A., Parsley, D. C., \& Wei, S. (2005). Slow passtrhough around the world: A new import for developing countries. NBER Working Papers, Massachusetts, 23, 213-251. Retrieved from 
http://www.link.springer.com/article/10.10072Fs11079-011-9210-8

Gang, F., Liping, H., \& Jiani, H. (2009). Cpi vs. ppi: Which drives which? Higher Education Press and Springer-Verlag., $\quad 4(3), \quad 317-334 . \quad$ Retrieved from http://link.springer.com/content/pdf/10.1007\%2Fs11459-009-0018-z.pdf

Ghazali, M., Yee, O., \& Muhammed, M. (2008). Do producer prices cause consumer prices? some emprical evidence. International Journal of Business and Management, 3(11), 78-82. Retrieved from http://www.ccsenet.org/journal/index.php/ijbm/article/view/907/0

Granger, C. W. J. (1969). Investigating causal relationships by econometric models and cross-spectral models. Econometrica, 37(3), 424-438.

Huertas, C., \& Jalil, B. M. (2000). Relación entre el índice de precios del productor (IPP) y el índice de precios al consumidor (IPC). Borradores de Economía (144), Banco de la República de Colombia. Retrieved from http://www.banrep.gov.co/publicaciones/pub borra.htm

Jin, X. (2012). An empirical study of exchange rate pass-through in china. Panoeconomicus, 2, 135-156. Retrieved from http://ideas.repec.org/a/voj/journl/v59y2012i2p135\{156.html

Lehmann, E., \& Romano, J. (2005). Testing Statistical Hypotheses (3rd ed.). Springer, Verlag.

Lemmens, A., Croux, C., \& Dekimpe, M. G. (2008). Measuring and testing granger causality over the spectrum: An application european production expectation surveys. International Journal of Forecasting, 24, 414-431.

Lutkepohl, H. (2009). Forecasting aggregated time series variables a survey. Department of Economics, European University Institute, Via della Piazzola 43, I-50133 Firenze, Italy.

Martínez, W. (2010). Construcción de un índice coincidente por medio de factores comunes dinámicos. Post-graduate Paper, Universidad Nacional de Colombia. Retrieved from http://www.bdigital.unal.edu.co/3089/1/wilmerosvaldomartinezrivera.2010.pdf

Martínez, W., Caicedo, E., \& Tique, E. (2012). Explorando la relación entre el ipc e ipp: el caso colombiano. Borradores de Economía (737), Banco de la República de Colombia. Retrieved from http://www.banrep.gov.co/publicaciones/pub borra.htm

Muhammad, S., Kumar, A., \& Mohammad, I. T. (1969). Does cpi granger-cause ppi? new extensions from frequency domain approach in pakistan. Munich Personal RePEc Archive (MPRA) (38816). Retrieved from http://mpra.ub.uni-muenchen.de/38816/

Sidaoui J., Capistran, C., \& Chiquiar, D. (2010). On the predictive content of the ppi on cpi ination: the case of mexico. Bank for International Settlements Papers, 49, 249-257.

Toda, H., \& Yamamoto, T. (1995). Statistical inference in vector autoregressions with possibly integrated processes. Journal of Econometrics, 66, 225-250. http://dx.doi.org/10.2307/2951647

\section{Notes}

Note 1. The PPI has been calculated in Colombia since 1948. Beginning that year and up to November 2006, the publication of this index was the responsibility of Banco de la República. Since then, DANE has been in charge of its estimation and monthly publication.

Note 2. For more details on the methodological differences between the PPI and the CPI, see Martinez et al. (2012).

Note 3. For more details, see Bry and Boschan (1971) and for a summary of this article, see Martinez (2010).

Note 4. Thirteen turning points $(\mathrm{Q}=13)$ were used to calculate the height of each of the bars.

Note 5. See Muhammad et al. (2012).

Note 6. Also, some experts suggest the PPI should anticipate the dynamic of the CPI, because it can be considered a proxy of the production costs that could potentially modify the performance of the final sale prices.

Note 7. The weights assigned to both baskets are those used in the current CPI methodology. Additionally, after homogenization between the two baskets, only 100 of the 181 items are present in both baskets, with an equivalent weight of $41.7 \%$ (CPI-100 y PPI-100).

Note 8 . It is important to note that services are not included in any of the groups in question.

Note 9. The goods classified as tradable are those whose prices are linked closely to movement in international 
prices and the exchange rate, and are internationally traded.

Note 10. See Frankel, et al. (2005), Jin (2012). For the Colombian case, see Caicedo (2006).

\section{Copyrights}

Copyright for this article is retained by the author(s), with first publication rights granted to the journal.

This is an open-access article distributed under the terms and conditions of the Creative Commons Attribution license (http://creativecommons.org/licenses/by/3.0/). 